\title{
CRESCIMENTO E PRODUTIVIDADE DE CULTIVARES DE SOJA EM FUNÇÃO DEDENSIDADES DE SEMEADURA
}

\author{
REGINI, Damião ${ }^{1}$ \\ PELLIN, Douglas Martins Pereira ${ }^{2}$ \\ SILVA JUNIOR, Carlos Antonio $\mathrm{da}^{3}$ \\ FINAMORE, Wilson Luiz de Miranda ${ }^{4}$ \\ MONTANARI, Rafael ${ }^{5}$
}

RESUMO: O presente trabalho objetivou avaliar o desempenho vegetativo e produtivo de duas cultivares de soja em diferentes densidades de semeadura, indicados para a região do município de Dourados, MS. O delineamento experimental implantado foi o de blocos casualizados em esquema fatorial 6 × 2 (seis densidades de semeadura: 12, 18, 24, 30, 36 e 42 sementesm $^{-1}$ e duas cultivares: BRS 255 RR (crescimento determinado) e BMX TITAN RR (crescimento indeterminado) com três repetições. Os componentes avaliados foram: altura de plantas, altura de inserção da primeira vagem, peso de 100 grãos e produtividade. Houve efeito significativo apenas para a variável altura de planta para a interação cultivares e densidade. Para as demais variáveis, não houve efeito significativo para as interações. Os componentes vegetativos, altura de plantas, inserção da primeira vagem e massa de 100grãos, apresentaram maiores valores nas densidades de 24 e 30 sementesm $^{-1}$; sendo a cultivar BRASMAX TITAN RR ${ }^{\circledR}$.

Palavras-chave: Componentes do rendimento. Densidade de plantas. GlycinemaxL.

\section{GROWTH AND YIELD OF SOYBEAN CULTIVARS IN SOWING DENSITY FUNCTION}

SUMMARY: The present study aimed to evaluate the vegetative and productive performance of two soybean cultivars in different sowing densities, suitable for the region of the municipality of Dourados, MS, Brazil. The experiment was implemented in a randomized block factorial $6 \times 2$ (six sowing densities: 12, 18, 24, 30, 36 and 42 seeds $\mathrm{m}^{-1}$ and two cultivars: BRS $255 \mathrm{RR}$ (growth determined) and BMX TITAN RR (indeterminate growth) with three replications. The components evaluated were: plant height, height of insertion of the first pod, weight 100 grains and productivity. Significant effect only to the variable plant height for interaction cultivars and density. For all other variables, there was no significant effect for the interactions. The vegetative components, plant height, insert the first pod and mass of 100 grains, had the highest values in densities of 24 and 30 seeds $\mathrm{m}^{-1}$; being to cultivate BRASMAX TITAN RR.

Keywords: Yield components. Plant density. Glycinemax L.

\section{INTRODUÇÃO}

A cultura da soja ocupa posição de destaque na agricultura brasileira, com área cultivada de 24,2 milhões de hectares e uma produção em torno de 72,3 milhões de toneladas, com importância nas

\footnotetext{
${ }^{1}$ Engenheiro-Agrônomo, Centro Universitário da Grande Dourados (UNIGRAN), Dourados, MS, Brasil. E-mail: damiao.regini@yahoo.com.br.

${ }^{2}$ Engenheiro-Agrônomo, Mestrando em Produção Vegetal, Universidade Estadual de Mato Grosso do Sul (UEMS), Aquidauana, MS, Brasil. E-mail: douglas.martins@agronomo.eng.br.

${ }^{3}$ Engenheiro-Agrônomo, Mestrando em Sensoriamento Remoto, Instituto Nacional de Pesquisas Espaciais (INPE), São José dos Campos, SP, Brasil. E-mail: carlosjr@dsr.inpe.br.

${ }^{4}$ Mestre em Agronomia, Professor do Centro Universitário da Grande Dourados (UNIGRAN), Dourados, MS, Brasil. E-mail: wilsonlm@terra.com.br.

${ }^{5}$ Professor Doutor da Universidade Estadual de Mato Grosso do Sul (UEMS), Aquidauana, MS, Brasil. E-mail: rafamontana@hotmail.com.
} 
exportações agrícolas (CONAB, 2011), assim sendo o segundo maior produtor mundial da cultura com $20,1 \%$ de toda a produção dessa leguminosa no mundo. As áreas de cerrado, por suas condições topográficas e seu clima favorável, ocupam posição de destaque no cenário nacional com sua produção (EMBRAPA, 2000).

A produtividade da cultura é definida pela interação entre planta, ambiente de produção e manejo. Dentre as práticas de manejo, a época de semeadura, escolha da cultivar, espaçamento e densidade de semeadura são fatores que influenciam no rendimento e seus componentes da produção (MAUAD et al., 2010)

A densidade de semeadura é fator determinante para o arranjo das plantas no ambiente de produção e influencia diretamente o crescimento da soja (MARTINS et al., 1999). Além disso, ela interfere na competição inter e intraespecífica por recursos do solo, especialmente água e nutrientes, além de provocar mudanças morfofisiológicas nas plantas (ARGENTA et al., 2001).

Características morfofisiológicas, tais como número de ramos por planta, comprimento de ramos e números de nós férteis, têm relação com o potencial produtivo da planta de soja, uma vez que representam maior superfície fotossintetizante e também potencialmente produtiva por meio do número de locais para surgimento de gemas reprodutivas. Por outro lado, o número e comprimento de ramos podem representar demanda adicional que desvia os fotoassimilados que, de outra forma, seriam aproveitados na fixação e na produção de estruturas reprodutivas (NAVARRO JÚNIOR \&COSTA, 2002). Até a década de 1908, era comum cultivar soja com 400 mil plantas ha ${ }^{-1}$ ou até mais, na qual essas variações pouco influenciavam o rendimento dos grãos, entretanto com o desenvolvimento de novos cultivares de soja faz-se necessário o estudo de populações na cultura (COPETTI, 2003).

Nos casos em que o aumento da população de plantas causa efeito acentuado no acamamento das plantas, populações elevadas podem levar a redução no rendimento de grãos. Variações entre 200 e 500 mil plantas $\mathrm{ha}^{-1}$, normalmente, não influenciam o rendimento de grãos ou faz muito pouco, aumentando ou reduzindo, dependendo de diversos fatores como clima, ano, época de semeadura, cultivar e fertilidade do solo (EMBRAPA, 2008).

Estudos com o objetivo de avaliar o efeito da densidade de semeadura na linha em relação aos componentes vegetativos e da produção da cultura da soja, é observado que no aumento do estande final de plantas $\mathrm{ha}^{-1}$ há aumento proporcional na altura de plantas e no rendimento de grãos (MAUAD et al., 2010; PEIXOTO et al., 2000).

Segundo Mauad et al. (2010) quando trabalhado com densidades de 10,12, 14, 16 e 18 plantas $\mathrm{m}^{-1}$ utilizando a cultivar Coodetec - 219 RR e espaçamento de $0,45 \mathrm{~m}$, foi observado que a menor densidade originou plantas com maior número de ramificações e menor altura de inserção da primeira vagem em plantas. Entretanto, os melhores rendimentos de grãos por vagem foram obtidos com a densidade de 10 a 12 plantas $\mathrm{m}^{-1}$ para a cultivar estudada, sendo a massa de grãos não influenciada pelas densidades trabalhadas.

Segundo Pires et al. (1998), população de plantas que variam de 8 a 63 plantasm $^{-2}$ não têm mostrado efeito no rendimento de grãos, o que está relacionado com plasticidade fenotípica da cultura. Assim, as plantas de soja compensam a redução da densidade, por aumentarem a produção individual de legumes, o que contribui para maior tolerância a essa variação. Estudos realizados por Pelúzio et al. (2010), apresentam que densidades de semeadura de 6 e 14 sementesm $^{-1}$ definem uma maior produção de grãos para a região norte.

Levando-se em consideração os aspectos abordados sobre os efeitos da densidade de semeadura e comportamento de cultivares, o objetivo deste trabalho foi avaliar o efeito do comportamento de alguns componentes vegetativos e da produção de cultivares de soja sob diferentes densidades de semeadura. 


\section{MATERIAL E MÉTODOS}

O estudo foi realizado no ano agrícola 2009/2010, na área experimental da Faculdade de Ciências Exatas e da Terra do Centro Universitário da Grande Dourados - UNIGRAN, $22^{\circ} 12^{\prime} \mathrm{S}$ e $54^{\circ} 52^{\prime} \mathrm{Wa}$ uma altitude média de $438 \mathrm{~m}$, localizada no município de Dourados, Mato Grosso do Sul. O clima da região segundo classificação de Köppen-Geiger é do tipo Cwa (clima mesotérmico úmido, verões quentes e invernos secos), com precipitação média anual de $1.200 \mathrm{~mm} \mathrm{ano}^{-1}$, com a temperatura do mês mais frio inferior a $18^{\circ} \mathrm{C}$ e a do mês mais quente superior a $22^{\circ} \mathrm{C}$ (FIETZ\&FISCH,2008). O solo da área experimental foi classificado como LATOSSOLO VERMELHO distroférrico (EMBRAPA, 2006).

O delineamento experimental utilizado foi de blocos ao acaso em parcela subdividida com três repetições. Os tratamentos foram constituídos por seis densidades de plantio, sendo elas: 12, 18, 24, 30, 36 e 42 sementesm $^{-1}$ e duas cultivares de soja: BRS $255 \mathrm{RR}^{\circledR}$ (crescimento determinado, maturação precoce e requer baixa população de plantas) e a BMX TITAN $\mathrm{RR}^{\circledR}$ (crescimento indeterminado, semiprecoce, e elevado potencial produtivo).

As sementes foram tratadas com inseticida, fungicidas e micronutrientes; no momento da semeadura, as sementes foram inoculadas com Bradyrhizobiumjaponicum, na proporção de $0,5 \mathrm{~kg}$ de inoculante para50 kg de sementes e junto ao plantio realizou-se a aplicação de $60 \mathrm{~kg} \mathrm{ha}^{-1}$ de $\mathrm{P}_{2} \mathrm{O}_{5}$ e $30 \mathrm{~kg}$ $\mathrm{ha}^{-1}$ de $\mathrm{K}_{2} \mathrm{O}$, na fórmula 0-20-20. A semeadura foi realizada manualmente, de acordo com a densidade programada. O controle de plantas daninhas, pragas e doenças, quando necessário foi realizado utilizando métodos de controle químico, de acordo com as recomendações técnicas da cultura (EMBRAPA, 2008).

As parcelas foram compostas por sete linhas de seis metros, com espaçamento de $0,45 \mathrm{~m}$ entre linhas e com intervalos de $0,5 \mathrm{~m}$ entre parcelas. Sendo consideradas como parcela útil, para as amostragens, as três linhas centrais e excluindo um metro em cada extremidade como bordadura.

As variáveis estudadas foram: ALT.: altura de planta; PROD.: produtividade; IPV: inserção da primeira vagem; MCG: massa de 100grãos; onde foram realizadas conforme metodologia indicada de análise de sementes proposta pelo Ministério da Agricultura (BRASIL, 2009).

Os dados obtidos foram submetidos à análise de variância. Para comparar os resultados dos atributos estudados em relação às cultivares de soja, utilizou-se o teste de Tukey a 1 e $5 \%$ de probabilidade, através do programa estatístico SAS (SAS INSTITUTE, 1999). Mediante análises de regressão por função polinomial, foram ajustadas equações de regressão aos dados obtidos, a partir do peso de cem grãos e produtividade, adotando-se como critério para escolha do modelo a magnitude dos coeficientes de determinação, significativos a 1 e $5 \%$.

\section{RESULTADOS E DISCUSSÃO}

A análise de variância para as características agronômicas e produtividade estão apresentadas na Tabela 1. Observando os coeficientes de variação, nota-se que a maioria dos valores apresentaram-se "baixos", sendo evidenciada uma boa condução e coleta dos dados experimentais (PIMENTEL-GOMES, 1990). 
Tabela 1. Análise de variância (F) para densidades (D) relacionadas às cultivares(C). Dourados, MS, 2010.

\begin{tabular}{ccccc}
\hline Fonte de Variação & ALT. $^{1}$ & PROD. & IPV & MCG \\
\hline D & $0,96^{* *}$ & $0,13^{\mathrm{ns}}$ & $1,89^{\mathrm{ns}}$ & $8,08^{* * *}$ \\
C & $33,71^{* *}$ & $1,27^{\mathrm{ns}}$ & $19,02^{*}$ & $24,50^{\mathrm{ns}}$ \\
D x C & $0,12^{*}$ & $1,42^{\mathrm{ns}}$ & $2,25^{\mathrm{ns}}$ & $0,85^{\mathrm{ns}}$ \\
\hline CV $(\%)-\mathrm{D}$ & 6,64 & 14,27 & 12,60 & 3,62 \\
CV $(\%)-\mathrm{C}$ & 10,25 & 24,60 & 16,25 & 3,18 \\
\hline
\end{tabular}

${ }^{1}$ ALT.: altura de planta; PROD.: produtividade; IPV: inserção da primeira vagem; MCG: massa de 100 grãos; ${ }^{\text {ns }}$ Não significativo. ${ }^{* * * *}$ Significativo a 5 e $1 \%$ de probabilidade pelo teste $\mathrm{F}$, respectivamente.

Houve efeito significativo apenas para a variável altura de planta para a interação cultivares e densidade (Tabela 1). Para as demais variáveis, não houve efeito significativo para as interações. No entanto, as cultivares apresentaram comportamento diferenciado, sendo observada, maior altura para a cultivar BRASMAX TITAN RR ${ }^{\circledR}$ principalmente nas densidades de semeadura de 24 e 30 sementesm $^{-1}$, com uma média geral de 111,33 cm(Tabela 2), possivelmente devido seu hábito de crescimento indeterminado.

No caso da cultura da soja, o acúmulo de plantas em alguns pontos pode provocar o desenvolvimento de plantas mais altas, menos ramificadas, com menor produção individual, diâmetro de haste reduzido e, portanto mais propensas ao acamamento (ENDRES, 1996). Por outro lado, espaços vazios deixados na linha, além de facilitar o desenvolvimento de plantas daninhas, levam ao estabelecimento de plantas de soja com porte reduzido. O estande produzido dessa forma pode acarretar redução na produtividade, além das dificuldades por ocasião da colheita mecanizada (EMBRAPA, 2008).

Conforme estudos realizados por Tourino et al. (2002), afirmam que em menores densidades de plantio, as plantas de soja apresentam-se mais baixas e acamam menos, ocasionando assim uma menor taxa de sobrevivência, já densidades maiores, mostram-se mais propensas a redução do acamamento e maiores produtividades de grãos.

Tabela 2.Componentes vegetativos e produtividade da planta e densidade de plantio para as cultivares estudadas. Dourados, MS, 2010

\begin{tabular}{cccccccc}
\hline \multirow{2}{*}{ Parâmetros } & \multirow{2}{*}{ Cultivar } & \multicolumn{7}{c}{ Densidades $\left(\right.$ sementesm $\left.^{-1}\right)$} \\
\cline { 3 - 8 } & & 12 & 18 & 24 & 30 & 36 & 42 \\
\hline \multirow{2}{*}{ ALT. $(\mathrm{cm})$} & BRS & $85,00 \mathrm{bA}^{2}$ & $88,33 \mathrm{bA}$ & $91,67 \mathrm{bA}$ & $95,00 \mathrm{bA}$ & $90,00 \mathrm{bA}$ & $89,00 \mathrm{bA}$ \\
& BMX & $105,67 \mathrm{aA}$ & $110,33 \mathrm{aA}$ & $111,33 \mathrm{aA}$ & $111,33 \mathrm{aA}$ & $110,00 \mathrm{aA}$ & $109,00 \mathrm{aA}$ \\
\hline PROD. & BRS & $3.130 \mathrm{Aa}$ & $3.383 \mathrm{aA}$ & $3.120 \mathrm{aA}$ & $2.644 \mathrm{aA}$ & $2.776 \mathrm{aA}$ & $3.128 \mathrm{aA}$ \\
$\left(\mathrm{kg} \mathrm{ha}^{-1}\right)$ & BMX & $3.231 \mathrm{Aa}$ & $3.149 \mathrm{aA}$ & $3.369 \mathrm{aA}$ & $3.612 \mathrm{aA}$ & $3.429 \mathrm{aA}$ & $3.154 \mathrm{aA}$ \\
\hline \multirow{2}{*}{ IPV $(\mathrm{cm})$} & BRS & $12,67 \mathrm{aA}$ & $14,33 \mathrm{aA}$ & $15,33 \mathrm{aA}$ & $14,00 \mathrm{aA}$ & $15,33 \mathrm{aA}$ & $16,67 \mathrm{aA}$ \\
& BMX & $20,33 \mathrm{Aa}$ & $17,33 \mathrm{aA}$ & $22,00 \mathrm{aA}$ & $16,67 \mathrm{aA}$ & $17,67 \mathrm{aA}$ & $18,00 \mathrm{aA}$ \\
\hline \multirow{2}{*}{ MCG (g) } & BRS & $13,00 \mathrm{aA}$ & $14,67 \mathrm{aA}$ & $15,00 \mathrm{aA}$ & $15,00 \mathrm{aA}$ & $14,33 \mathrm{aA}$ & $14,67 \mathrm{aA}$ \\
& BMX & $14,33 \mathrm{aA}$ & $15,00 \mathrm{aA}$ & $16,00 \mathrm{aA}$ & $15,33 \mathrm{aA}$ & $15,33 \mathrm{aA}$ & $15,33 \mathrm{aA}$ \\
\hline
\end{tabular}

${ }^{\mathrm{I}}$ ALT.: altura de planta; PROD.: produtividade; IPV: inserção da primeira vagem; MCG: massa de 100 grãos; 2BRS: BRS $255 \mathrm{RR}^{\circledR}$; BMX: BRASMAX TITAN RR ${ }^{\circledR} ;{ }^{3}$ Letra maiúscula compara as densidades na mesma cultivar; letra minúscula compara a densidade nas cultivares; médias seguidas de mesma letra não diferem entre si pelo teste de Tukey $(\mathrm{p}<0,05 ; \mathrm{p}<0,01)$. 
Para inserção da primeira vagem, o comportamento foi semelhante, não havendo efeito da densidade e novamente apresentando efeito para as cultivares (Tabela 2), assim sendo esperado, pois a inserção de vagens é uma característica de alta herdabilidade, ou seja, aquela que é determinada por muitos gens e pouco influenciada pelo meio (FONSECA et al., 2004).

A massa de 100 grãos foi principalmente influenciada pelas cultivares em questão e suas respectivas densidades de semeadura (Tabela 2). Ainda apontando para a variável MCG, possivelmente foi influenciada pelas características agronômicas da cultura, assim, onde foi realizada maior densidade de semeadura, houve a diminuição no tamanho do grão, mas compensando com maior quantidade (Figura 1). Já a diferença entre as cultivares, é habitual a BRASMAX TITAN RR ${ }^{\circledR}$ possuir maior peso de grãos, já que a BRS $255 \mathrm{RR}^{\circledR}$ apresenta o grão mais leve.

Figura 1. Curvas polinomiais para massa de 100 grãos em função das diferentes densidades para as cultivares BRS (A) e BMX (B), na região de Dourados, MS, ajustadas pela função polinomial de $3^{\circ}$ ordem $\left({ }^{* *}\right.$ significância a $1 \% ;{ }^{*}$ significância a $5 \%$ pelo teste $\left.\mathrm{t}\right)$.
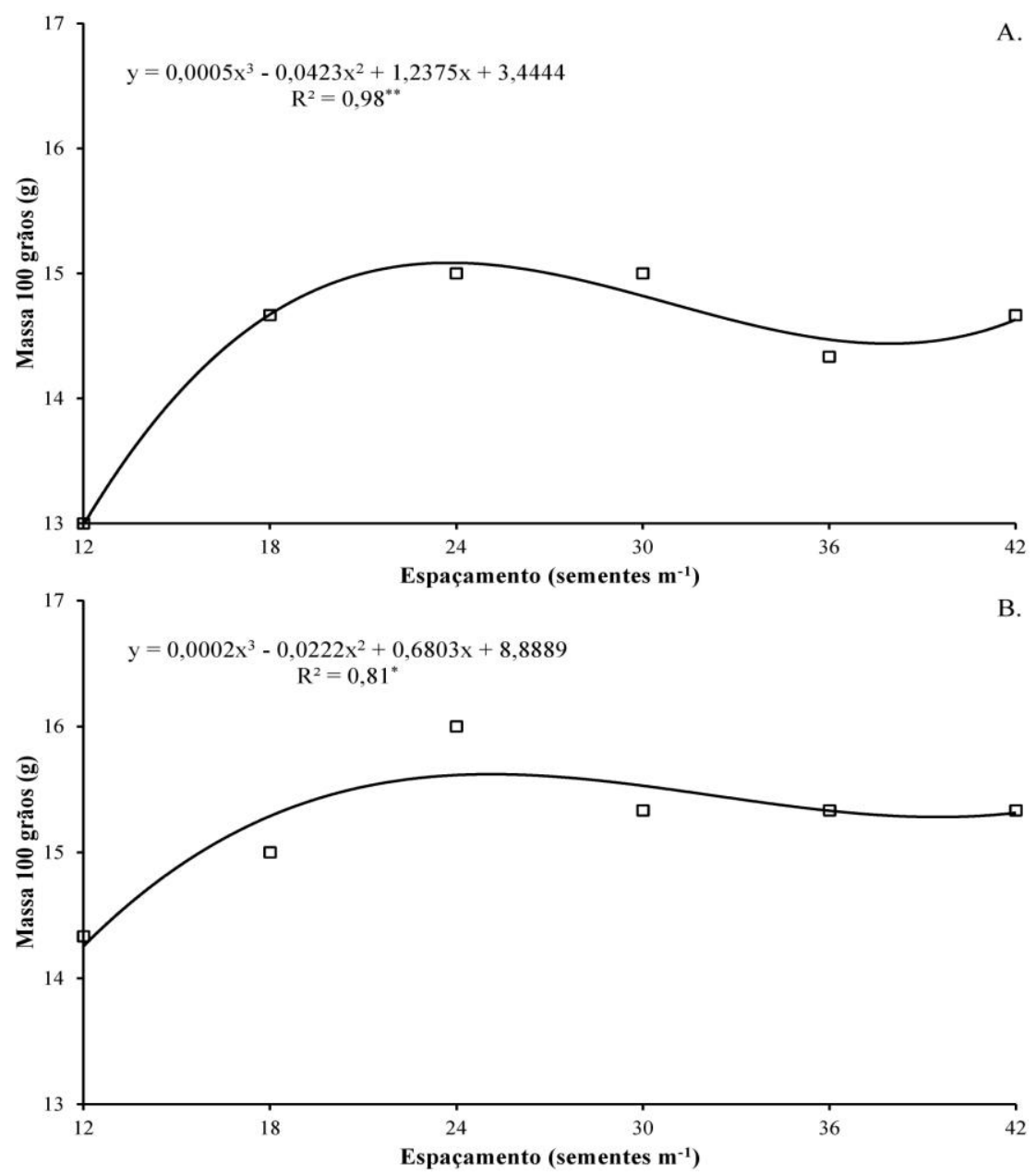

A variável massa de 100 grãos para as cultivares em questão apresentou comportamento cúbico com relação às densidades de semeadura, em que a maior MCG $(16,00 \mathrm{~g})$ foi obtida com 24 sementes $\mathrm{m}^{-1}$ para a cultivar BMX TITAN RR ${ }^{\circledR}$ (Figura 1B).

As diferentes densidades e cultivares não influenciaram significativamente a produtividade (Tabela 1). Esse resultado provavelmente está relacionado às condições meteorológicas favoráveis, 
ocorridas durante o período experimental. Cambui et al. (2007) estudando diferentes arranjos e densidades também não observaram diferenças na produtividade, devendo estar relacionado a outras características como número de ramificações e outros componentes de produção. Segundo Peixoto (1998), as plantas de soja compensam a redução da densidade por aumentarem a produção individual de legumes, o que contribui para maior tolerância a essa variação.

O comportamento em relação à produtividade de grãos pode ser observado pela Figura 2. Para a cultivar BRS $255 \mathrm{RR}^{\circledR}$ o aumento significativo foi na densidade de 18 e 42 sementesm $^{-1}$, com uma produção média de 3.383 e $3.128 \mathrm{~kg} \mathrm{ha}^{-1}$ (Tabela 2), respectivamente. Já para a cultivar BRASMAX TITAN $\mathrm{RR}^{\circledR}$ o resultado foi o inverso, apresentando melhores produtividades nas densidades 30 e 36 sementesm ${ }^{-1}$.
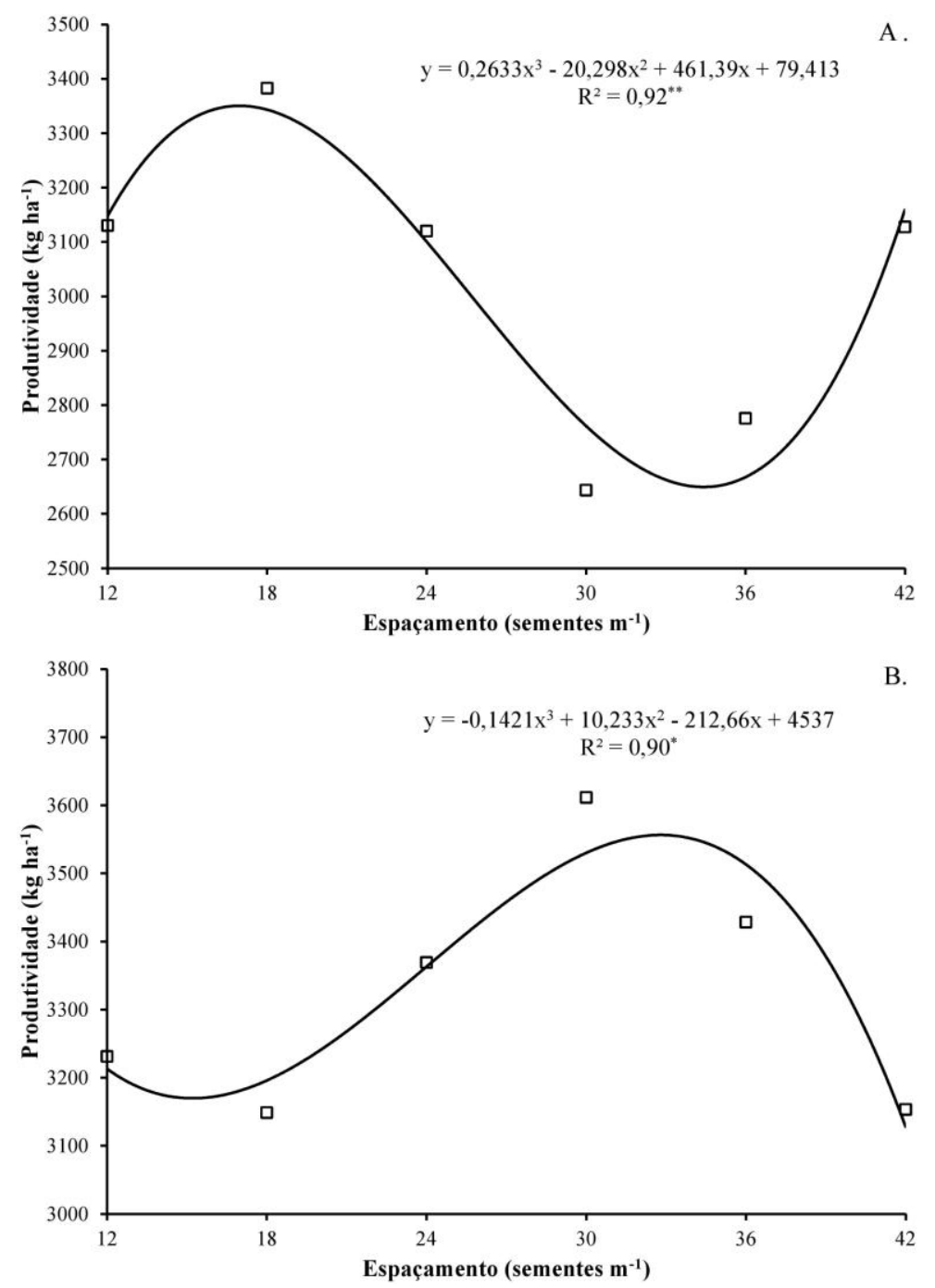

Figura 2. Curvas polinomiais para produtividade em função das diferentes densidades para as cultivares BRS (A) e BMX (B), na região de Dourados, MS, ajustadas pela função polinomial de $3^{\circ}$ ordem ( ${ }^{* *}$ significância a $1 \% ;$; significância a $5 \%$ pelo teste t).

A variável produtividade para as cultivares em questão apresentou comportamento cúbico com relação às densidades de semeadura, onde a maior produção $\left(3.612 \mathrm{~kg} \mathrm{ha}^{-1}\right)$ foi obtida com 30 sementes $\mathrm{m}^{-1}$ para a cultivar BMX TITAN RR ${ }^{\circledR}$ (Figura 2B).

Em relação aos efeitos que não foram significativo em relação à densidade de semeadura sobre as características agronômicas estudadas pode ser explicada por Fonseca et al. (2004), onde afirmam que as características agronômicas de alta herdabilidade são pouco influenciadas pelo ambiente. Nos trabalhos 
relacionados à seleção genotípica para diversas espécies vegetais, comumente observa-se que tais características possuem alta herdabilidade (ALVES et al., 2006; CAMBUI et al., 2007).

\section{CONCLUSÃO}

Os componentes vegetativos, altura de plantas, inserção da primeira vagem e massade 100grãos, apresentaram maiores valores nas densidades de 24 e 30 sementesm $^{-1}$; sendo a cultivar BRASMAX TITAN RR ${ }^{\circledR}$;

Apesar da variável produtividade não ter apresentado significância em função da densidade de semeadura, a cultivar BMX TITAN $\mathrm{RR}^{\circledR}$ apresentou em sua maioria valores superiores aos da cultivar BRS $255 \mathrm{RR}^{\circledR}$.

\section{REFERÊNCIAS}

ALVES, J. C. S.; et al. Herdabilidade e correlações genotípicas entre caracteres de folhagem e sistema radicular em famílias de cenoura, cultivar Brasília. Horticultura Brasileira, Campinas-SP, v.24, n.3, p.363-367, 2006.

ARGENTA, G.; SILVA, P.R.F.; SANGOL, L. Arranjo de plantas em milho: análise do estado-da-arte. Ciência Rural, Santa Maria - RS, v.31, n.6, p.1075-1084, 2001.

BRASIL, Ministério da Agricultura, Pecuária e Abastecimento. Secretaria de defesa Agropecuária. Regras para análise de sementes. Brasília, 399p. 2009.

CAMBUI, E. V. F.; ARAGÃO, W. M.; LEAL, M. L. S. Variabilidade genética entre cultivares de coqueiro anão (Cocos nucifera L. - Var. Nana). Revista Brasileira de Biociências, Porto Alegre - RS, v.5, n.1, p.165-167, 2007.

COMPANHIA NACIONAL DE ABASTECIMENTO - CONAB. Produção e Produtividade, Safras de soja 2010/2011 - $7^{\circ}$ Levantamento, abril de 2011. Disponível em: <

http://www.conab.gov.br/OlalaCMS/uploads/arquivos/11_04_07_11_02_42_boletim_abril-2011..pdf>. Acesso em: 15 de nov. de 2011.

COPETTI, E. Plantadoras: Distribuição de sementes. Cultivar Máquinas. V.18, p.14-17 2003.

CRUZ, T. V.; PEIXOTO, P. C.; MARTINS, C. M. Crescimento e produtividade de soja em diferentes épocas de semeadura no oeste da Bahia. Scientia Agraria, Curitiba-PR, v.11, n.1, p.033-042, 2010.

EMBRAPA. Centro Nacional de Pesquisa de Soja (Londrina, PR). Recomendações técnicas para a cultura da soja no Paraná: safra 2000/2001. Londrina, 2000. 255p.

EMBRAPA. Tecnologias de produção de soja - Região central do Brasil. Londrina: Embrapa soja: Embrapa Cerrados: Embrapa Agropecuária Oeste, 2008. 262p.

EMPRESA BRASILEIRA DE PESQUISA AGROPECUÁRIA - EMBRAPA. Sistema Brasileiro de Classificação de Solos. 2.ed. Rio de Janeiro, 2006. 306p.

ENDRES, V. C. Espaçamento, densidade e época de semeadura. In: EMBRAPA. Centro de Pesquisa Agropecuária do Oeste (Dourados, MS). Soja: recomendações técnicas para Mato Grosso do Sul e Mato Grosso. Dourados, 1996. p. 82-85. (Circular Técnica, 3). 
FIETZ, C. R.; FISCH, G. F. O Clima da região de Dourados, MS. Dourados: Embrapa Agropecuária Oeste, 2008. 32p.

FONSECA, J. R.; et al. Descritores morfoagronômicos e fenológicos de cultivares tradicionais de arroz coletados no Maranhão. Revista Ceres, Viçosa-MG, v.51, n.293, p.45-56, 2004.

MARTINS, M.C.; et al. Épocas de semeadura, densidades de plantas e desempenho vegetativo de cultivares de soja. Scientia Agricola, Piracicaba-SP, v.56, n.4, p.851-858, 1999.

MAUAD, M.; et al. Influência da densidade de semeadura sobre características agronômicas na cultura da soja. Agrarian, Dourados-MS, v.3, n.9, p.175-181, 2010.

NAVARRO JÚNIOR, H. M.; COSTA, J. A. Contribuição relativa dos componentes do rendimento para produção de grãos em soja. Pesquisa Agropecuária Brasileira, Brasília, v.37, n.3, p.269-274, 2002.

PEIXOTO, C. P.; et al. Épocas de semeadura e densidade de plantas de soja: I. Componentes da produção e rendimento de grãos.ScientiaAgricola, Piracicaba-SP,v.57, n.1, p.89-96, 2000.

PEIXOTO, C.P. Análise de crescimento e rendimento de três cultivares de soja (Glicynemax (L) Merrill) em três épocas de semeadura e três densidades de plantas. Tese 1998. Tese (Doutorado em Fitotecnia) - Escola Superior de Agricultura "Luiz de Queiroz" Universidade de São Paulo, Piracicaba, 1998.

PELÚZIO, J. M.; et al. Efeito da época e densidade de semeadura na produtividade de grãos de soja na Região Centro-Sul do estado do Tocantins. Pesquisa Aplicada \& Agrotecnologia, Guarapuava-PR, v.3, n.3, p.147-166, 2010.

PIMENTEL-GOMES, F. Curso de estatística experimental. 13 ed. Piracicaba: Nobel, 1990.467p.

PIRES, J.L.F.; COSTA, J.A.; THOMAS, A.L. Rendimento de grãos de soja influenciado pelo arranjo de plantas e níveis de adubação. Pesquisa Agropecuária Gaúcha, Porto Alegre-RS, v.4, n.2, p.183-188, 1998.

SAS - Estatistical Analysis System Institute. SAS/STAT Procedure guide for personal computers. 5ed. Cary, NC: SAS Inst. 1999. 334 p.

TOURINO, M. C. C.; REZENDE, P. M.; SALVADOR, N. Espaçamento, densidade e uniformidade de semeadura na produtividade e características agronômicas da soja. Pesquisa Agropecuária Brasileira, Brasília-DF, v.37, n.8, p.1071-1077, 2002. 